\title{
Sonographic measure techniques of fetal penile length
}

\author{
Álvaro López Soto, MD, PhD, Jose Luis Meseguer González, MD, Rocío López-Perez, MD, \\ Mónica Lorente Fernández, MD, Juan Martínez-Uriarte, MD, PhD, Olivia García Izquierdo, MD \\ Prenatal Diagnosis Unit, Hospital General Santa Lucía, Cartagena, Spain
}

Postnatal penile length is a reliable, standardized, and widely used marker for the diagnosis of genitourinary pathology, as well as genetic and hormonal disorders. In contrast, prenatal diagnosis has not been developed equally and there is a lack of relevant literature. Our objective is to review the studies on fetal penile length, and apply findings to clinical practice. Although the most used technique is the outer penile length, there is no consensus regarding the appropriate technique for prenatal measurement. Several reports have provided reference data with high correlation. However, important issues like poor correlation with post-natal measures or presence of confounding variables are still present. Diagnosis of both a micropenis and macropenis can indicate related pathologies, and this information may benefit parental counseling and facilitate fetal management. Therefore, it is necessary to carry out prospective studies that provide reliable normative data.

Keywords: Fetal ultrasonography; Micropenis; Hypospadias; Fetal therapy; Genital system

\section{Introduction}

For more than 80 years, systematic measurement of penile length has been done in newborns [1]. This reliable measure is the basis for the diagnosis of micropenis, a medical condition that in turn is a marker for many genetic syndromes, endocrinological disorders or structural malformations, which may require more complex studies, hormonal treatments or corrective surgeries [2]. Given its importance, all the information regarding measurement techniques, normative data, spectrum of anomalies, associated pathologies as well as clinical management has been developed for decades [3]. In contrast, prenatal diagnosis has not been developed equally and there is a lack of an equivalent source of knowledge. Therefore, our ability to make a diagnosis of micropenis and its related pathologies using this method is much more limited. Our objective was to review the existing literature on fetal penile length, focusing on measurement technique, practical challenges and limitations, and prenatal counseling.

\section{Embryology}

Typical development of the male external genitalia requires the presence of a normal $Y$ chromosome, an intact fetal hor- monal axis, and correct placentation that provides the necessary stimuli to operationalize the whole system. An aberration in any of these variables may cause genital anomalies.

During the initial stages of organogenesis, 3 basic structures are formed: bipotential gonads, genital passages, and indistinct external genitalia including the phallus and genital folds. Stimulation provided by the placental human chorionic gonadotropin causes the Leydig cells to produce testosterone as early as the 7th week of gestation [4]. The influence of this androgen results in sexual differentiation, due to which the phallus elongates to become a penis; genital folds fuse to form the scrotum, and the bipotential gonads form the testicles [5]. Placental function continues until the 14-15th

Received: 2020.04.10. Revised: 2020.05.31. Accepted: 2020.06.17. Corresponding author: Álvaro López Soto, MD, PhD

Prenatal Diagnosis Unit, Hospital General Santa Lucía, C/Mezquita 1, Cartagena 30202, Spain

E-mail: Alvarolopezsoto1@gmail.com

https://orcid.org/0000-0002-3314-0347

Articles published in Obstet Gynecol Sci are open-access, distributed under the terms of the Creative Commons Attribution Non-Commercial License (http://creativecommons. org/licenses/by-nc/3.0/) which permits unrestricted non-commercial use, distribution, and reproduction in any medium, provided the original work is properly cited.

Copyright $\odot 2020$ Korean Society of Obstetrics and Gynecology 


\section{Obstetrics \& Gynecology Science}

Vol. 63, No. 5, 2020

week of gestation, after which the production of testosterone becomes dependent on the stimulation of the fetal luteinizing hormone. External genitalia are completely formed by the 17-18th week [6], and continues to grow regularly until birth of the fetus [7].

\section{Anomalies in penile length}

\section{Micropenis}

Micropenis is defined as a penile length less than 2.5 standard deviations (SDs) from the mean [8]. This condition is distinguishable from other similar anomalies such as the small penis (above $2.5 \mathrm{SDs}$ ), penis agenesis, and buried penis. The last case is defined as a normal-sized penis surrounded by prepubic tissues that interfere with its measurement [9].

All these conditions indicate a wide variety of pathologies. We included alterations in urethral development, placental insufficiency, and the alterations of the hormonal axis or genetic syndromes. Urethral alterations are frequently associated with anomalies of the corpus spongiosum and/or corpora cavernosa that lead to an abnormal curvature of the penis, interfering in the measurement and giving a value lower than the real one [10]. Poor placentation can lead to an inadequate secretion of testosterone, causing the abnormal development of the genitals. There is also an association between delayed intrauterine growth and male genital anomalies [11]. In the series by Nemec et al. [12], all fetuses affected by CIR showed significant penile shortening. Regarding hormonal or genetic abnormalities, an alteration in the size of the penis can be the clinical manifestation of fetal endocrinopathies or genetic syndromes. Winter and Baraitser [13] reported in their genetic database a total of 369 syndromes, wherein the main finding was a micropenis.

\section{Macropenis}

Unlike the micropenis, there is no standardized term for a penis that is pathologically larger than normal, which also indicates possible pathologies. Terms such as "macropenis", "megapenis", or "enlarged penis" have been used. Additionally, there is no consensus regarding a cutoff point in reference tables. However, these cases do occur and indicate fetal pathology, as in the case of congenital megalourethra or congenital adrenal hyperplasia.

Congenital megalourethra is a rare urogenital malforma- tion characterized by dilatation of the urethra due to defects in the anterior urethral valves or hypoplasia of the corpora cavernosa. The review by Moaddab et al. [14] shows that, to date, approximately 50 cases have been published in literature Ultrasound shows a macropenis with an irregular dilation of the urethra, accompanied by other signs of urinary obstruction such as a megacystis, bilateral hydronephrosis, and keyhole sign. The prognosis can be severe, with severe pulmonary hypoplasia and renal impairment. However, it can resolve spontaneously in up to $10 \%$ of cases and is susceptible to fetal therapy [15].

Congenital adrenal hyperplasia is a disorder of the adrenal gland due to an enzymatic deficiency, and is characterized by a deficiency of cortisol and an excess of androgens. It's clinical presentation occurs over a broad spectrum with a classical form that can trigger a potentially lethal crisis in the first hours of life [16]. Excessive androgens are the primary cause of ambiguous genitalia in female fetuses, which is why the study of the hormonal profile in amniotic fluid is indicated [17]. In the case of male fetuses, Merke and Bornstein [18] describe in their review that a macropenis is a possible consequence, and include a photograph of a newborn aged 7-10 days with an enlarged penis. Despite this evidence, there are no fetal cases published to date.

\section{Measurement technique}

\section{Postnatal}

The methodology for measuring penile length during postnatal examination is fully established. First reports date back to 80 years ago, and since then there have been hardly any changes [1].

The main issue in measuring the penis in newborns and infants is the impossibility of getting an erect length, so instead the so-called stretched penis length or stretched penile length (SPL) is used [19]. It should be measured from the base of the penis at the pubic symphysis to the tip of the glans, gently stretching it to its maximum resistance, depressing the adjacent pubic fat, and measuring the entire dorsal aspect of the penis [20]. As with most anthropometric measures, there may be several confounding factors in the measurement. These are due to the extensibility and elasticity of the penis, so its length can vary significantly in response to thermal, tactile, and environmental changes [1]. 


\section{Obstetrics \& Gynecology Science}

Álvaro López Soto, et al. Sonographic measure fetal penile length

\section{Prenatal}

In comparison to postnatal measurement, there is no consensus regarding the techniques, measurements, and values for prenatal measurement [21]. Although we cannot make a physical examination like pediatricians, obstetric ultrasound allows the detailed evaluation of the male genitalia, including the size of the penis, the size of the scrotum, and the size and location of the testicles [22]. It is possible to measure variables of the penis such as its length, width, and diameter, as well as that of the comprising structures such as the corpus cavernosum, corpus spongiosum, and glans [23].

The most important question when it comes to measuring fetal penile length seems to be the features that should be used for measurement. Since the beginning, the classic measurement has been from the tip of the glans to the edge of the scrotum, also called the outer penile length (OPL) [12]. It is the measurement of the visible part, which is the simplest and most feasible to obtain. The vast majority of published studies use this measure to create their reference tables $[12,21,24-27]$. Its main drawback is that it is a partial measurement of the penis, which does not correspond to the postnatal measurement that accounts for the whole length. It can also lead to error in situations in which the fetal penis is normal in length but hidden by prepubic tissues such as the buried penis, penis palmatus, and in the presence of hernias or hydroceles [28].

Other authors have reported measurement strategies using alternative features. The length of the fetal penis has been measured from the tip of the glans to the pubic symphysis [12], to the proximal edge of the corpus cavernosum [29], and to the proximal edge of the corpus spongiosum [23]. Although correlation between OPL and these measures of "total penile length" was high and authors provided instructions for simplifying these measurements, no later work has repeated these methods. In fact, some authors have criticized these measurements as "impractical" due to the difficulty in correctly identifying said structures [24].

Technical issues such as angle of visualization, timing, frequency of measurement, and imaging modalities have barely been addressed. Most publications work with ultrasound using an axial plane; as explained by Johnson and Maxwell [26] a transducer that was angulated was used so that the penis was as horizontal as possible, allowing a clear view for measurement. On the other hand, Nemec et al. [12] criticized the use of axial and coronal planes since they did not allow suf- ficient visualization of the penis due to its curvature. Instead, the author recommended the measurement in a sagittal plane. It is noteworthy that his work on measurements of fetal penises is based on magnetic resonance imaging, rather than ultrasound [12].

There may be several confounding factors that affect the measurement such as the filling state of the bladder or fetal erections. However, Johnson and Maxwell [26] reported no significant differences between measurement with a full or empty bladder. In case of fetal erection, it is a phenomenon that has not been studied in detail. It is known that fetal penises can have erections due to factors such as changes in blood flow or contraction of the pelvic muscles [30], and that it is a relatively frequent finding in the third trimester to observe an average of 1 to 3 erections hourly [23] No work has specified whether the measurements in their references tables were made with relaxed or erect fetal penises, and the scope of bias that this introduces is unknown.

\section{Reference tables}

\section{Postnatal tables}

Postnatal reference tables have been fully consolidated over decades of research, starting from the works of Schonfield and Beebe [1] in the 1940s to the Feldman and Smith [3] regulations in the 1970s. The average SPL at birth is $35 \mathrm{~mm}$ and cutoff point for diagnosis of micropenis is a difference of more than 2.5 SDs or $25 \mathrm{~mm}$ [8]. In recent years, efforts have focused on individualizing normative data based on ethnicity due to important differences attributable to the place of birth [31-35] The nomogram of fetal length in Iranian neonates proposed by Soheilipour et al. [36], for example, shows a mean SPL of $22.48 \mathrm{~mm}$ at term, standing below the cutoff for a micropenis, as previously described.

Other equally important factors would be the gestational age at birth and the individual anthropometric measurements themselves. Penis growth closely follows the growth pattern of other measures such as body length, foot length, and neonatal weight; the length of the penis can be predicted based on foot length and neonatal weight taken jointly [37]. As with other growth curve studies, the focus in the future would on making more individualized predictions instead of reference populations tables. 


\section{Obstetrics \& Gynecology Science}

Vol. 63, No. 5, 2020

\section{Prenatal tables}

1) Penile length measurements using ultrasound Reference tables published to date are shown in Table 1. Mean penile length calculated using gestational age is shown in Fig. 1 [12,21,23-27,29].

The studies that have followed the OPL methodology, which represent more than half of all reports, show a very high correlation in the results. On the 20th week of gestation, for example, the maximum range of difference between means is less than $1 \mathrm{~mm}$, from average mean of $7.27 \mathrm{~mm}$ to $8.25 \mathrm{~mm}$ average mean. As the gestational age increases, so does the variability. The maximum difference at the 37th week of gestation is $6 \mathrm{~mm}$, between average mean of $18.9 \mathrm{~mm}$ and $25 \mathrm{~mm}$. Correlation observed between the OPL measurement and gestational age is high in all cases. We also note that the majority of studies report end at the threshold of $25 \mathrm{~mm}$, which is considered the traditional cutoff point for postnatal diagnosis of micropenis [8]. This reinforces the idea that OPL measurement, even if it is the most practical, does not represent the total length of the postnatal penis. However, direct measures in anatomic studies of Shen et al. [6] seem to correlate with OPL curves, challenging the previous hypothesis.

The series by Perlitz et al. [29], Vuillard et al. [23], and the second report by Nemec et al. [12] are not based on the OPL measure, but rather use alternative techniques. At first glance the results of Nemec et al. [12] come closest to reference measurements, since both are based on the measurement from the tip of the penis to the edge of the pubic symphysis. Measurement of the corpora cavernosum or corpus spongiosum, on the other hand, use very specific structures of the penis and do not seem to be useful for correlation with SPL.

\section{2) Challenges and limitations}

\section{Correlation between prenatal and postnatal measures}

Prenatal ultrasound measurements and direct postnatal measurement using SPL study the same parameter but utilize different approaches and methodologies. To date, only one work has made the comparison between pre and postnatal measures [38]. With a small sample of 46 male fetuses and using the OPL measure technique, penile lengths were

Table 1. Measurement of fetal penile length

\begin{tabular}{|c|c|c|c|c|c|c|c|c|c|c|c|}
\hline \multirow{2}{*}{ Population } & \multirow{2}{*}{$\begin{array}{l}\text { Size } \\
\text { study }\end{array}$} & \multirow{2}{*}{$\begin{array}{c}\text { Gestational } \\
\text { age (wk) }\end{array}$} & \multirow{2}{*}{$\begin{array}{l}\text { Measurement } \\
\text { technique }\end{array}$} & \multirow{2}{*}{ Year } & \multirow{2}{*}{ Study group } & \multicolumn{6}{|c|}{ Mean at each week (mm) } \\
\hline & & & & & & 15 & 20 & 25 & 30 & 35 & 40 \\
\hline Turkey & 179 & $17-37$ & $\mathrm{OPL}$ & 2016 & Akpinar et al. [24] & - & 7.9 & 10.7 & 13.5 & 17.0 & - \\
\hline Israel & 104 & $22-36$ & $\mathrm{OPL}$ & 2012 & Danon et al. [21] & - & - & 10.9 & 14.7 & 18.0 & - \\
\hline US & 494 & $14-41$ & $\mathrm{OPL}$ & 2003 & Pinette et al. [25] & - & 7.3 & 10.8 & 14.6 & 18.6 & 23.1 \\
\hline Israel & 419 & $14-38$ & OPL & 2001 & Zalel et al. [9] & 4.3 & 7.2 & 10.9 & 15.26 & 20.3 & - \\
\hline UK & 95 & $16-38$ & OPL & 2000 & $\begin{array}{l}\text { Johnson and } \\
\text { Maxwell [26] }\end{array}$ & - & 8.2 & 11.9 & 16.66 & 22.4 & - \\
\hline \multirow[t]{2}{*}{ Austria } & \multirow[t]{2}{*}{194} & \multirow[t]{2}{*}{$18-34$} & \multirow{2}{*}{$\begin{array}{l}\text { OPL, total penile } \\
\text { length }\end{array}$} & \multirow[t]{2}{*}{2012} & \multirow[t]{2}{*}{ Nemec et al. [12] } & - & 7.7 & 9.9 & 14.13 & - & - \\
\hline & & & & & & - & 18.2 & 23.9 & 33.13 & - & - \\
\hline \multirow[t]{2}{*}{ France } & \multirow[t]{2}{*}{486} & \multirow[t]{2}{*}{$18-40$} & \multirow{2}{*}{$\begin{array}{c}\text { OPL, corpus } \\
\text { spongiosum length }\end{array}$} & \multirow[t]{2}{*}{2011} & \multirow[t]{2}{*}{ Vuillard et al. [23] } & - & 7.7 & 12.4 & 17.1 & 21.8 & 26.6 \\
\hline & & & & & & - & 19.4 & 31.3 & 43.2 & 55.1 & 67.1 \\
\hline Israel & 242 & $14-35$ & $\begin{array}{c}\text { Corpus } \\
\text { cavernosum length }\end{array}$ & 2011 & Perlitz et al. [29] & 8.1 & 18.6 & 26.5 & 38.0 & 50.2 & - \\
\hline Australia & 188 & $24-36$ & SPL & 1998 & $\begin{array}{l}\text { Tuladhar et al. } \\
\text { [27] }\end{array}$ & - & - & 17.5 & 25.5 & 33.5 & - \\
\hline Iran & 587 & $30-41$ & SPL & 2018 & $\begin{array}{l}\text { Soheilipour et al. } \\
\qquad \text { [36] }\end{array}$ & - & - & - & 18.0 & 21.0 & 25.9 \\
\hline US & - & $8-22$ & Anatomic study & 2018 & Shen et al. [6] & 3.9 & 8.0 & - & - & - & - \\
\hline
\end{tabular}

OPL, outer penile length; SPL, stretched penile length. 


\section{Obstetrics \& Gynecology Science}

Álvaro López Soto, et al. Sonographic measure fetal penile length

compared both prenatally and postnatally. The result was a significant although weak correlation between pre and postnatal length, with a 0.32 coefficient of determination.

Fig. 1 shows the early measurements in the anatomic studies of Shen et al. [6] as well as the prenatal cutoff points, suggesting the real normative data should be a curve that met both scales. Further, different ultrasound measurements also shown in this figure do not resolve this problem $[6,8]$.

The inclusion of 2 reference tables of preterm and term newborns further complicates the situation $[27,36]$. Tuladhar et al. [27] show a parallel curve to the OPL series, with a maximum difference of approximately $10 \mathrm{~mm}$ that remains constant throughout all gestational ages, finishing at the 36th week of gestation with a mean of $34.7 \mathrm{~mm}$, which is very close to the postnatal mean in full-term infants at 35 mm [8]. However, Soheilipour et al. [36] show a similar curve to that of the OPL series, finishing at term with a mean of $22.9 \mathrm{~mm}$, considered as a micropenis. The first series corresponds to a western population, whereas the second one is for an Iranian population. Similarly, it should be considered if the data obtained for preterm newborns is biased due to premature birth.

\section{Lower limit of growth curve}

Comparison of the lower limit is difficult due to the heterogeneity of units of measurement and results. Ideally, the lower limit could be set at the 2.5 SDs used to diagnose a micropenis during the postnatal period. However, most of the studies use other references, including SDs, interquartile range, and the 2.5, 3.5, and 10 percentiles. Among those works that have used SDs, small sized samples have provided anomalous results and distorted curves. Only Pinette et al.

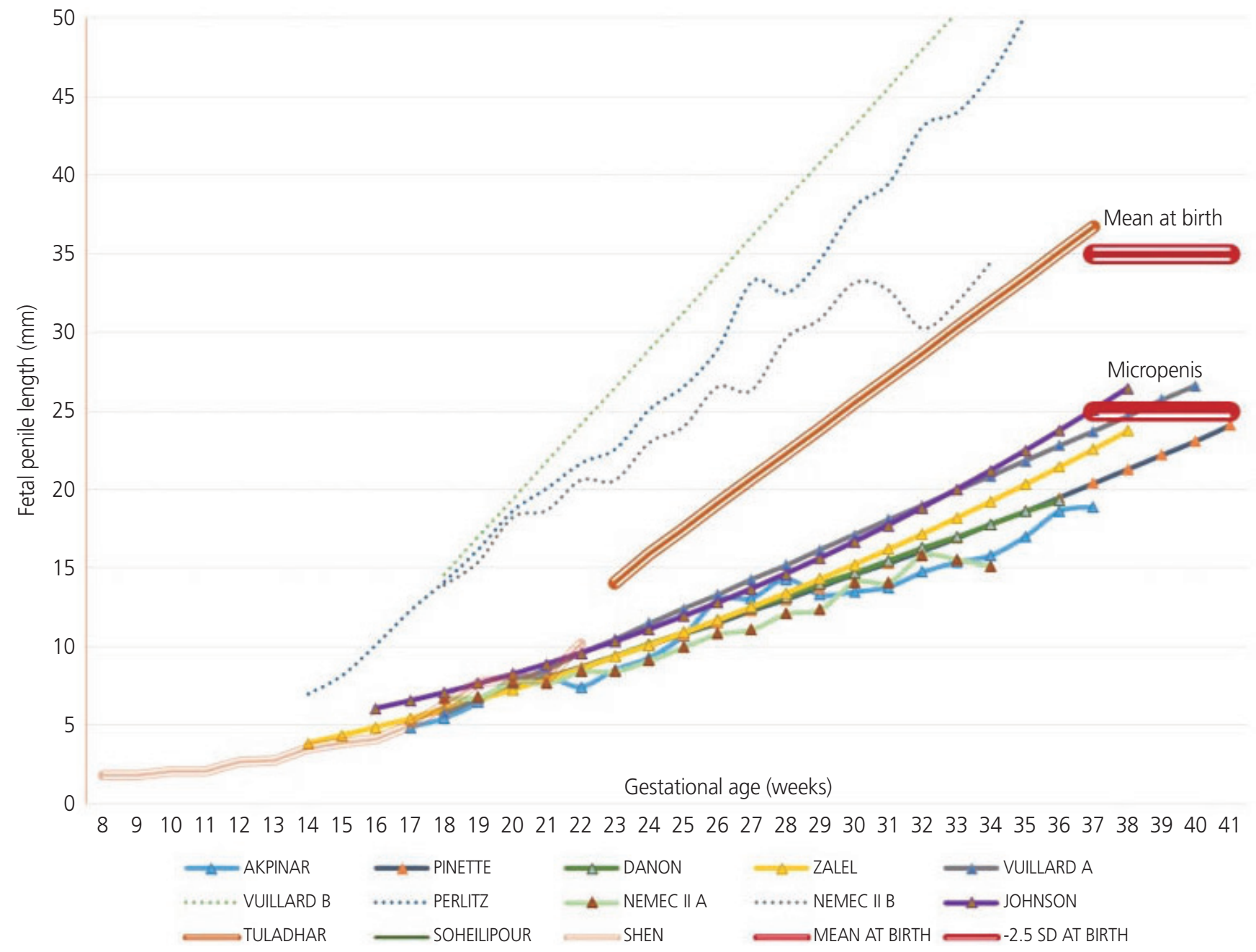

Fig. 1. Mean fetal penile length according to gestational age and study. 


\title{
Obstetrics \& Gynecology Science
}

\author{
Vol. 63, No. 5, 2020
}

[25], which uses the largest sample, has provided a reliable lower limit based on the SDs.

\section{Size of the samples}

No study has exceeded 500 cases. Study designs are not based on cohorts that are measured weekly, and rather are retrospective studies in which measurements are added based on gestational age and relationship formulas. Akpinar et al. [24], for example, uses a total sample of 179 fetuses with measurements distributed over 21 weeks. The result is that half of the calculated means are based on measurements of 6 fetuses or less. Although the results of most of the references tables are similar and appear to be reliable, it would be necessary to carry out prospective studies with a large cohort, wherein the measurements were longitudinal for each fetus.

\section{Gestational age}

Most studies start measuring in the second trimester, at which time fetal sex can be determined with certainty. The work of Zalel et al. [9] began early, with measurements in the 14th week of gestation. Most studies finalize the measurements before reaching term, and only the works of Akpinar et al. [24] and Pinette et al. [25] continued until the 40th week of gestation.

\section{Ethnic group}

This is an important factor when establishing reference values, with significant differences between groups such as Caucasians and Asians $[8,31,32]$. However, there is no ethnic diversity in the samples used to date, with the exception of Akpinar et al. [24], who used a sample population of Turkish origin. The remaining studies are based on Caucasian populations from western countries and Israel.

\section{Other measurements}

The use of a single measure for the assessment of the penis poses problems such as the distinction between a small penis or a prominent clitoris [25]. Various complementary measurements have been proposed such as width, diameter, or even curvature of the penis, associated with the presence of hypospadias [10]. Katorza et al. [39] proposed the dynamic use of ultrasound and Doppler mode, which would allow the observation of male urination by locating the urine stream at the tip of the penis, ruling out the diagnosis of hypospadias.

The most promising measure would be the measurement of the width of the penis, introduced by Danon et al. [21]. Authors describe it as a measurement that is easily performed, with good correlation with length; they also provided the first reference table [21]. Akpinar et al. [24] replicate the same methodology with similar results. The main reason for the width measurement is that is provides greater specificity for the micropenis diagnosis, since a micropenis has a normal tubular shape, such that reduced length is accompanied by proportional reduction in width.

\section{Clinical practice}

Due to the limitations of the available studies and the current technical challenges, it is not possible to establish normative values or implement the routine measurement of the fetal penis using a mid-trimester ultrasound; the same has been concluded in different international guidelines $[40,41]$. Nevertheless, we could use the available evidence as guidance or in selected cases (Fig. 2). In these situations, the OPL measurement technique may be used, measuring the penis from the tip of the glans to the edge of the scrotum. The axial plane seems to be the most used and it would be appropriate for measuring the penis as horizontal as possible. As cutoff points, average length of the penis between 19 weeks and 22 weeks would be 7 to $10 \mathrm{~mm}$, and a micropenis diagnosis would be below $4 \mathrm{~mm}$. There is no consensus on the measure for diagnosing a macropenis. The corpora cavernosa and/or corpus spongiosum could be measured according to the Vuillard et al. [23] or Perlitz et al. [29] technique, respectively, to rule out a normal-sized penis buried between prepubic tissues. Penile width could also be measured using the Danon et al. [21] reference table.

A diagnosis of macropenis would mainly suggest a congenital megalourethra, so an anatomical scan of the urinary system should be done to observe signs such as a dilated and irregular urethra, megacystis, hydronephrosis, and anhydramnios. Genetic amniocentesis is a mandatory test prior to being a candidate for fetal therapy, even though irreversible damage and poor performance of fetal cystoscopy results in a high rate of termination of pregnancy [42]. The finding of a large penis with normal morphology and no other ana- 


\section{Obstetrics \& Gynecology Science}

Álvaro López Soto, et al. Sonographic measure fetal penile length

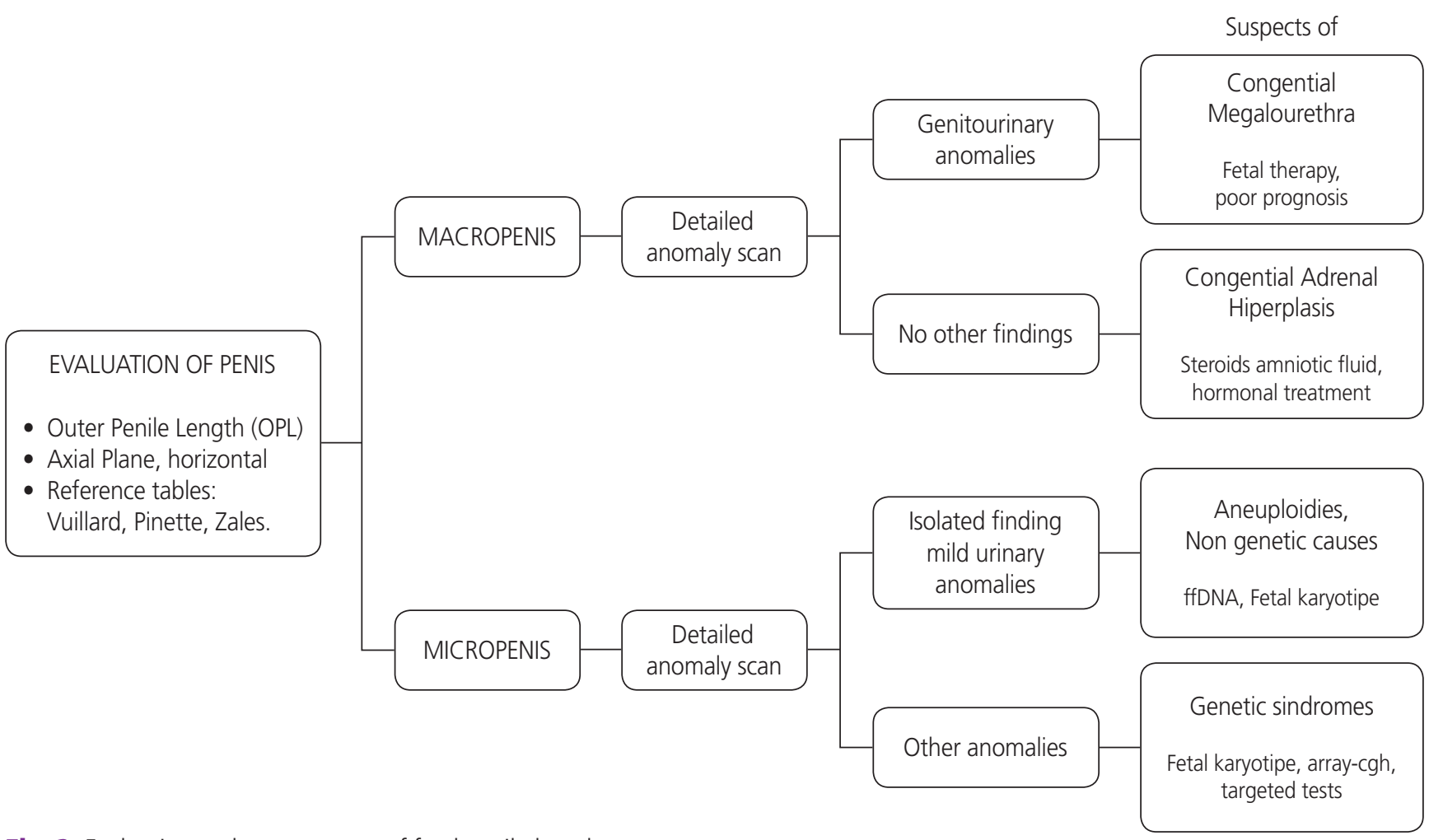

Fig. 2. Evaluation and management of fetal penile length.

tomical findings in the scan could guide us to a diagnosis of congenital adrenal hyperplasia. In this situation, amniocentesis for fetal karyotyping should be considered, as well as a study of steroid metabolites in the amniotic fluid [17]. This diagnosis requires the evaluation of an endocrinologist, use of hormonal treatment, and such diagnoses in severe cases can help prevent sudden death in the first days of postnatal life [43].

The diagnosis of micropenis is related to a much greater range of pathologies, as we have previously seen. In this case, the diagnostic work-up proposed by Pajkrt et al. [17] that includes a detailed scan and the use of genetic tests would be useful. The first step includes a detailed anomaly scan, focusing on the urinary system, and an assessment of fetal growth. The second step consists of the selection of a genetic test based on previous findings, to determine if the isolated findings or mild urinary anomalies are more related to chromosomal abnormalities or non-genetic pathologies; the finding of various anatomical abnormalities could indicate several genetic syndromes [17].

Depending on the results, it may be necessary to refer the patient to urology, endocrinology, clinical geneticist, or even to engage a multidisciplinary team to manage disorders of sexual development [44]. Isolated genitourinary anomalies such as anterior hypospadias would result in an early consultation with a pediatric urologist, facilitating a correct postnatal follow-up plan [45]. Endocrinopathies such as congenital adrenal hyperplasia could require a change in the birth plan, or reference to a specialized center to enable access to multidisciplinary teams in case of emergency issues such as gender of rearing [46]. Prenatal interventions like hormonal manipulation or fetoscopy for lower urinary tract obstructions are not being used systematically, and are currently limited to investigations [47]. The diagnosis of genetic syndromes with high morbidity and mortality could lead to parents choosing to terminate the pregnancy [48]. Therefore, incorrect diagnosis of the fetal penis length could have important short- and long-term implications.

However, due to poor knowledge in this area of prenatal medicine, it is crucial to be cautious when making a diagnosis and providing counseling information. Such diagnoses can cause considerable anxiety in parents, and may be a cause for the termination of pregnancy [38]. 


\section{Obstetrics \& Gynecology Science}

Vol. 63, No. 5, 2020

\section{Conclusion}

Postnatal penile length is a standardized, widely used, and a reliable marker for the diagnosis of genitourinary pathology, as well as genetic and hormonal disorders. Although the most studied technique is the OPL, there is no consensus regarding the technique appropriate for prenatal measurement. Even though it is not considered normative data, we can assume OPL cutoff points in the second trimester, as seen using an ultrasound, to be an average of 7-10 mm with a lower limit of $4 \mathrm{~mm}$. The presence of both a micropenis and a macropenis can be associated with relevant pathologies. It is necessary to carry out prospective studies with sufficient sample sizes and using a common measurement system, so as to create more comprehensive reference tables.

\section{Conflict of interest}

No potential conflict of interest relevant to this article was reported.

\section{Ethical approval}

The study was approved by the Hospital General Santa Lucia Ethical Committee and performed in accordance with the principles of the Declaration of Helsinki. Written informed consents were obtained.

\section{Patient consent}

The patients provided written informed consent for the publication and the use of their images.

\section{References}

1. Schonfield WA, Beebe GW. Normal growth and variation in the male genitalia from birth to maturity. J Urol 1942;48:759-77.

2. Hatipoğlu N, Kurtoğlu S. Micropenis: etiology, diagnosis and treatment approaches. J Clin Res Pediatr Endocrinol 2013;5:217-23.
3. Feldman KW, Smith DW. Fetal phallic growth and penile standards for newborn male infants. J Pediatr 1975;86:395-8.

4. Makiyan Z. Systematization of ambiguous genitalia. Organogenesis 2016;12:169-82.

5. Marshall FF. Embryology of the lower genitourinary tract. Urol Clin North Am 1978;5:3-15.

6. Shen J, Cunha GR, Sinclair A, Cao M, Isaacson D, Baskin $\mathrm{L}$. Macroscopic whole-mounts of the developing human fetal urogenital-genital tract: indifferent stage to male and female differentiation. Differentiation 2018;103:513.

7. Migeon CJ, Wisniewski AB. Congenital adrenal hyperplasia owing to 21-hydroxylase deficiency. Growth, development, and therapeutic considerations. Endocrinol Metab Clin North Am 2001;30:193-206.

8. Cheng PK, Chanoine JP. Should the definition of micropenis vary according to ethnicity? Horm Res 2001;55:278-81.

9. Zalel Y, Pinhas-Hamiel O, Lipitz S, Mashiach S, Achiron $R$. The development of the fetal penis--an in utero sonographic evaluation. Ultrasound Obstet Gynecol 2001;17:129-31.

10. Lin SK, Lee YH, Pong HC, Ho ES. Prenatal diagnosis of a rare variant of hypospadias and review of the literature. Ultrasound Obstet Gynecol 2001;18:678-80.

11. Yinon $Y$, Kingdom JCP, Proctor LK, Kelly EN, Salle JLP, Wherrett $D$, et al. Hypospadias in males with intrauterine growth restriction due to placental insufficiency: the placental role in the embryogenesis of male external genitalia. Am J Med Genet A 2010;152A:75-83.

12. Nemec SF, Nemec U, Weber M, Brugger PC, Bettelheim $D$, Rotmensch $S$, et al. Penile biometry on prenatal magnetic resonance imaging. Ultrasound Obstet Gynecol 2012;39:330-5.

13. Winter RM, Baraitser M. The London dysmorphology database. 5th ed. Oxford: Oxford University Press; 2001.

14. Moaddab A, Sananes N, Hernandez-Ruano S, Werneck Britto IS, Blumenfeld $Y$, Stoll F, et al. Prenatal diagnosis and perinatal outcomes of congenital megalourethra: a multicenter cohort study and systematic review of the literature. J Ultrasound Med 2015;34:2057-64.

15. Wax JR, Pinette MG, Landes A, Cartin A, Blackstone J. Prenatal sonographic diagnosis of congenital megalourethra with in utero spontaneous resolution. J Ultrasound 


\section{Obstetrics \& Gynecology Science}

Álvaro López Soto, et al. Sonographic measure fetal penile length

Med 2009;28:1385-8.

16. Huynh T, McGown I, Cowley D, Nyunt O, Leong GM, Harris $M$, et al. The clinical and biochemical spectrum of congenital adrenal hyperplasia secondary to 21-hydroxylase deficiency. Clin Biochem Rev 2009;30:75-86.

17. Pajkrt E, Petersen OB, Chitty LS. Fetal genital anomalies: an aid to diagnosis. Prenat Diagn 2008;28:389-98.

18. Merke DP, Bornstein SR. Congenital adrenal hyperplasia. Lancet 2005;365:2125-36.

19. Wessells H, Lue TF, McAninch JW. Penile length in the flaccid and erect states: guidelines for penile augmentation. J Urol 1996;156:995-7.

20. Kollurage UA, Atapattu N, Jayamanne BD, Gunasiri JR, de Silva SH. Assessment of the stretched penile length in Sri Lankan newborns. Ceylon Med J 2019;64:4-8.

21. Danon D, Ben-Shitrit G, Bardin R, Machiach R, Vardimon $D$, Meizner I. Reference values for fetal penile length and width from 22 to 36 gestational weeks. Prenat Diagn 2012;32:829-32.

22. Rotondi M, Valenzano F, Bilancioni E, Spanò G, Rotondi M, Giorlandino C. Prenatal measurement of testicular diameter by ultrasonography: development of fetal male gender and evaluation of testicular descent. Prenat Diagn 2001;21:112-5.

23. Vuillard E, Chitrit $Y$, Dreux S, Elghoneimi A, Oury JF, Muller $F$. Sonographic measurement of corpus spongiosum in male fetuses. Prenat Diagn 2011;31:1160-3.

24. Akpinar F, Yilmaz S, Akdag Cirik D, Kayikcioglu F, Dilbaz $B$, Yucel $H$, et al. Sonographic assessment of the fetal penile development. Fetal Pediatr Pathol 2016;35:88-92.

25. Pinette MG, Wax JR, Blackstone J, Cartin A. Normal growth and development of fetal external genitalia demonstrated by sonography. J Clin Ultrasound 2003;31:465-72.

26. Johnson P, Maxwell D. Fetal penile length. Ultrasound Obstet Gynecol 2000;15:308-10.

27. Tuladhar R, Davis PG, Batch J, Doyle LW. Establishment of a normal range of penile length in preterm infants. J Paediatr Child Health 1998;34:471-3.

28. Radhakrishnan J, Razzaq A, Manickam K. Concealed penis. Pediatr Surg Int 2002;18:668-72.

29. Perlitz Y, Keselman L, Haddad S, Mukary M, Izhaki I, Ben-Ami M. Prenatal sonographic evaluation of the penile length. Prenat Diagn 2011;31:1283-5.

30. Jakobovits AA. Fetal penile erection. Ultrasound Obstet
Gynecol 2001;18:405.

31. Vasudevan G, Manivarmane R, Bhat BV, Bhatia BD, Kumar $S$. Genital standards for south Indian male newborns. Indian J Pediatr 1995;62:593-6.

32. Ponchietti R, Mondaini N, Bonafè M, Di Loro F, Biscioni $S$, Masieri L. Penile length and circumference: a study on 3,300 young Italian males. Eur Urol 2001;39:183-6.

33. Fok TF, Hon KL, So HK, Wong E, Ng PC, Chang A, et al. Normative data of penile length for term Chinese newborns. Biol Neonate 2005;87:242-5.

34. Al-Herbish AS. Standard penile size for normal full term newborns in the Saudi population. Saudi Med J 2002;23:314-6.

35. Lian WB, Lee WR, Ho LY. Penile length of newborns in Singapore. J Pediatr Endocrinol Metab 2000;13:55-62.

36. Soheilipour F, Rohani F, Dehkordi EH, Isa Tafreshi R, Mohagheghi $P$, Zaheriani SM, et al. The nomogram of penile length and circumference in Iranian term and preterm neonates. Front Endocrinol (Lausanne) 2018;9:126.

37. Bhakhri BK, Meena SS, Rawat M, Datta V. Neonatal stretched penile length: relationship with gestational maturity and anthropometric parameters at birth. Paediatr Int Child Health 2015;35:53-5.

38. Sharony R, Bental YA, Eyal O, Biron-Shental T, Weisbrod $M$, Shiff $Y$, et al. Correlation between prenatal and postnatal penile and clitoral measurements. J Clin Ultrasound 2012;40:394-8.

39. Katorza E, Pinhas-Hamiel O, Mazkereth R, Gilboa Y, Achiron R. Sex differentiation disorders (SDD) prenatal sonographic diagnosis, genetic and hormonal work-up. Pediatr Endocrinol Rev 2009;7:12-21.

40. Salomon LJ, Alfirevic Z, Berghella V, Bilardo C, Hernandez-Andrade E, Johnsen SL, et al. Practice guidelines for performance of the routine mid-trimester fetal ultrasound scan. Ultrasound Obstet Gynecol 2011;37:11626.

41. Reddy UM, Abuhamad AZ, Levine D, Saade GR; Fetal Imaging Workshop Invited Participants. Fetal imaging: executive summary of a joint Eunice Kennedy Shriver National Institute of Child Health and Human Development, Society for Maternal-Fetal Medicine, American Institute of Ultrasound in Medicine, American College of Obstetricians and Gynecologists, American College of Radiology, Society for Pediatric Radiology, and Society of Radiologists in ultrasound fetal imaging workshop. Ob- 


\section{Obstetrics \& Gynecology Science}

Vol. 63, No. 5, 2020

stet Gynecol 2014;123:1070-82.

42. Anh DD, Nguyen HT, Meagher S, Araujo Júnior E. Prenatal diagnosis of congenital megalourethra in the second trimester of pregnancy. J Ultrason 2019;19:302-4.

43. Khanal D, Mandal D, Phuyal R, Adhikari U. Congenital adrenal hyperplasia with salt wasting crisis: a case report. JNMA J Nepal Med Assoc 2020;58:56-8.

44. Lee PA, Houk CP, Ahmed SF, Hughes IA; International Consensus Conference on Intersex organized by the Lawson Wilkins Pediatric Endocrine Society and the European Society for Paediatric Endocrinology. Consensus statement on management of intersex disorders. International Consensus Conference on Intersex. Pediatrics 2006;118:e488-500.

45. Epelboym Y, Estrada C, Estroff J. Ultrasound diagnosis of fetal hypospadias: accuracy and outcomes. J Pediatr Urol 2017;13:484.e1-4.

46. Ahmed SF, Achermann JC, Arlt W, Balen A, Conway G, Edwards Z, et al. Society for Endocrinology UK guidance on the initial evaluation of an infant or an adolescent with a suspected disorder of sex development (revised 2015). Clin Endocrinol (Oxf) 2016;84:771-88.

47. Nef S, Neuhaus TJ, Spartà G, Weitz M, Buder K, Wisser $J$, et al. Outcome after prenatal diagnosis of congenital anomalies of the kidney and urinary tract. Eur J Pediatr 2016;175:667-76.

48. Graziani RNA, Nemzer L, Kerns J. The experience of genetic counselors working with patients facing the decision of pregnancy termination after 24 weeks gestation. J Genet Couns 2018;27:626-34. 